\title{
A ACP E A TOMADA DE DECISÃO EM INVESTIMENTOS
}

Tatiana Renaux Tomaselli ${ }^{\star}$

\section{Resumo}

As finanças comportamentais vêm mostrando divergências entre o comportamento do investidor e a teoria econômica. Este artigo apresenta uma forma de compreensão dos aspectos emocionais da decisão humana através da abordagem centrada na pessoa. Este enfoque mostra como decisões são tomadas de modos diferentes, com base no sentido que cada investidor atribui à realidade. $O$ sentido varia de acordo com a percepção de cada um sobre sua experiência. Investidores com maior maturação psicológica tomam decisões mais assertivas e flexíveis, modificandoas com mais rapidez quando novos dados da realidade forem surgindo.

Palavras-chave: Abordagem Centrada na Pessoa; tomada de decisão; Psicologia econômica; Psicologia do investidor.

\section{Person-Centered Approach and investments DECISION MAKING}

\begin{abstract}
Behavioral finances have been showing differences between investor behavior and the economic theory. This article sets out an understanding of the emotional aspects of the human decision process through the person-centered approach. The focus shows how decisions differ according to the meaning each investor attributes to his "reality" based on his/her personal perception and experience. Investors with a higher psychological maturity take more assertive and flexible decisions and are quicker to react more when fresh data throws new light on reality.
\end{abstract}

Keywords: Person-Centered Approach; decision making; economic psychology; investor psychology.

\footnotetext{
^ Bacharel em Administração (FURB - Universidade de Blumenau), Psicóloga (Unisul - Universidade do Sul de Santa Catarina), Especialista em Psicossomática (Instituto Brasileiro de Estudos Homeopáticos), Especialista em Psicologia Clínica (Instituto Delphos). Endereço: Rua Tenente Silveira, 675 - Centro Ed Dona Elza sala 101. Florianópolis, SC - Brasil. CEP: 88010-301. E-mail: tatianarenaux@hotmail.com
} 


\section{Os INVESTIDORES E A FORMAÇÃo dE PREÇOS NO MERCADO ACIONÁRIO}

Investidores do mercado acionário podem ser pessoas de qualquer área do conhecimento, jovens, aposentados, profissionais adultos ou donas de casa. Não há pré-requisito para se tornar um investidor, basta dispor de algum capital para começar. Entretanto, como explicam Cavalcante Filho e Misumi (2001), investir neste mercado envolve sempre algum grau de risco, pois só saberemos o quanto vamos ganhar na hora em que vendemos nossas ações, sendo possível também perder dinheiro com elas. As decisões de investimento são tomadas pelos investidores todos os dias, durante o pregão da Bolsa de Valores, e suas expectativas é que fazem os preços se modificarem. De acordo com Fleuriet (2004), quando os investidores estão otimistas sobre o futuro das empresas, compram, o que faz os preços subirem, quando mantêm expectativas pessimistas, vende, fazendo os preços caírem.

A economia estuda como os preços se formam no mercado acionário. Diferente da psicologia, onde temos várias abordagens teóricas distintas, a economia se sustenta sobre uma teoria principal, ou mainstream, conhecida como teoria da utilidade esperada. $\mathrm{O}$ agente econômico, também chamado de tomador de decisão (decision maker), dentro desta perspectiva, é um "indivíduo autocentrado, egoísta, otimizador de sua utilidade e capaz de fazer as melhores escolhas possíveis, a partir das informações de que dispõe, além de aprender com a experiência" (FERREIRA, 2008 p. 37). Em outras palavras, do ponto de vista econômico o investidor tomaria sempre suas decisões de investimentos considerando o melhor retorno financeiro possível, depois de verificar todas as informações disponíveis para ele. Além disso, quando um investimento resulta em prejuízo ele aprenderia com a própria experiência como maximizar o valor do seu ganho financeiro, assim, da próxima vez, não cometeria os mesmos erros. Na teoria econômica, todos os investidores agiriam da mesma forma e, como explica Milanez (2003), o único objetivo seria o lucro, não importando se fosse para mudar de emprego ou para comprar ações (STERNBERG, 2000). O que a psicologia chama de subjetividade e que faz com que interpretemos os fatos de modo diferente uns dos outros, a economia considera como "anomalias". As anomalias seriam resultantes da racionalidade limitada de alguns investidores que não conseguem tomar decisões da maneira que propõe a teoria econômica, ou seja, maximizando os lucros.

A partir de 2002, uma nova disciplina vem ganhando força dentro dos estudos em finanças estudando estas "anomalias", as quais fazem com que as decisões de investimentos não sigam à risca as regras da teoria econômica predominante (CASTRO JUNIOR; FAMÁ, 2002). Neste ano, o psicólogo cognitivo Kahneman ganhou o prêmio Nobel de Economia pelo estudo realizado em conjunto com seu colega Tversky entre os anos de 1937 a 1996, apresentando uma nova proposta para a compreensão da tomada de decisão econômica. Os autores estudaram as causas destas anomalias, utilizando-se do referencial teórico da psicologia cognitiva, e mostraram que o homem não é racionalmente limitado nem racionalmente científico. Para eles existem dois sistemas cognitivos que agem em conjunto quando tomamos decisões. O sistema 1, que inclui a intuição e a percepção, e o sistema 2, que compreende a razão. O sistema 1 é o primeiro que 
nos vem à mente quando entramos em contato com os fatos, por isso é espontâneo, não exige nenhum esforço. Já a razão é mais lenta e exige que façamos algum esforço para utilizá-la, como consultar um mapa ou resolver um problema matemático (KAHNEMAN, 2002, 2003).

As finanças comportamentais vêm ganhando espaço no Brasil. É comum encontrarmos trabalhos de mestrado e doutorado sobre o tema, bem como artigos no jornal Valor Econômico (2000- ) e nos manuais de análise de investimentos, por exemplo, Damodaran $(2006,2007)$. A maioria destes trabalhos é realizada por pessoas ligadas às finanças utilizando o referencial teórico da psicologia cognitiva. Bem poucos trabalhos são realizados por psicólogos no Brasil sendo uma exceção o modelo apresentado por Ferreira (2008), sob o olhar psicanalítico. Em outros países, a psicologia econômica, ciência que reúne psicólogos interessados na interface entre a economia e a psicologia, está ganhando espaço. Nos EUA já existe inclusive uma revista, chamada Journal of Economic Psychology (1981- ) dedicada ao tema. A psicologia econômica, conforme Ferreira (2008), estuda o comportamento econômico dos indivíduos, grupos e governo, no intuito de compreender a influência tanto da economia sobre o indivíduo, como dos indivíduos sobre a economia. Para isto estudam as crenças, sentimentos, atitudes, pensamentos e expectativas que influenciam na tomada de decisão humana, com foco nas decisões econômicas (FERREIRA, 2008).

\section{A TOMAda de DeCis̃̃o e A PERCEPÇÃo}

Quando se fala em decisão, pressupõe-se que a pessoa tenha conhecimento da situação sobre a qual precisa decidir, das opções possíveis e suas prováveis consequências (DAMÁSIO, 2007). O conhecimento que se tem de uma situação é sempre dependente da percepção da pessoa envolvida. Como podemos ler na definição de Ferreira (2008, p. 145), decidir é:

Ato que se apóia nos passos antecedentes da percepção e avaliação das condições oferecidas, constitui a essência dos atos humanos, ao reunir a capacidade de captar informações, analisá-las e ponderar sobre elas, abrindo caminho, assim, para a função especial do pensar, que seguido pelo agir, pode criar e transformar.

Decidir envolve sempre a nossa percepção sobre os fatos. Com a percepção verificamos as informações que estão disponíveis no meio. Depois avaliamos estas informações para podermos escolher o caminho a seguir. O comportamento na direção escolhida, seja dizer uma frase ou tomar uma atitude, é resultado deste processo inicial e, portanto, dependente da percepção. Assim, para entendermos o processo de decisão de cada investidor precisamos entender como ele percebe a situação e suas conseqüências.

Forghieri (1993) explica que percebemos as coisas em relação com aquilo que somos e não como um objeto que está fora de nós, completamente separado. Não que os fatos não existam por si só, mas eles são apenas fatos, e não são 
os fatos que afetam as pessoas e sim a forma como elas os percebem (BELLO, 2006). Em outras palavras, é dentro da vivência imediata do ser humano que as coisas adquirem sentido para quem está vivenciando a situação (FORGHIERI, 1993) e o que ele experiencia da situação é tomado como referência para as situações que se sucedem em sua vida (CAVALCANTE JUNIOR, 2008). Como nos diz Rogers e Kinget (1977, p. 197):

Sem dúvida, a relação da criança (e também do adulto) com seu meio estão em função de uma troca contínua entre os dados acumulados da sua experiência e os dados imediatos. [E por isso,] A realidade que afeta seu comportamento em cada momento particular é, [...] a realidade vivida.

Vejamos um exemplo no caso dos investimentos. Quando ocorre uma queda de preço de $2 \%$ nas ações da Vale no pregão, isto é um fato, não há como negar. No entanto, quando o investidor olha para esta queda para decidir se vende, compra, fica posicionado ou não faz nada, não é o fato da queda que interfere na sua tomada de decisão. O que importa e justifica que ele tome uma atitude é o significado desta queda para o investidor que está experienciando-a. Por exemplo, se ele tiver as ações da Vale na sua carteira, isto terá um significado. A princípio pode parecer ruim, mas vai depender do valor que pagou por elas. Por outro lado, se ele estiver vendido isto terá outro significado, talvez seja um fato sem importância; se não tivesse pensando em comprar estas ações, se ele tivesse esperando pelo momento oportuno de entrar, o significado seria outro, totalmente diferente. Agora vamos pensar num investidor que comprou estas ações quando elas estavam valendo bem menos que agora, e as vendeu, com alto lucro, justamente no dia anterior da queda. É possível que interpretará este fato com muita alegria ou mesmo euforia, sentindo-se o "bom", ou ainda como uma "benção de Deus", caso a religião tenha uma importância grande na sua vida.

Não há como esgotar todas as possibilidades e todos os sentidos, só podem ser descritos se estivermos em relação com aquele investidor, o exemplo é apenas para mostrar como a vivência de cada um proporciona uma visão diferente da situação que está ocorrendo. E como explica Fleuriet (2004), se não fosse assim não haveria negócios no pregão, pois o que faz os preços oscilarem no mercado acionário é justamente a diferença de opiniões entre compradores e vendedores. A mesma divergência que forma os preços no pregão.

\section{A abordagem Centrada na Pessoa e a tomada de decisão}

O nosso objetivo neste trabalho é mostrar como a Abordagem Centrada na Pessoa, apesar de não ter uma teoria específica para explicar a tomada de decisão humana, pode ser utilizada para compreendermos como ocorrem as escolhas ao longo da vida. Rogers (2001b) descreve sete fases que explicam como acontece a mudança terapêutica durante um processo de psicoterapia, ao mesmo tempo em que mostram a forma como a dinâmica da personalidade se expressa. Em outras palavras, as fases também podem nos fornecer um modo de compreender como as pessoas agem. 
Rogers (2001b), quando explicou o processo, que descreveremos abaixo, mostrou que a mudança não se encaminha para um ponto estático final de funcionamento ótimo da personalidade, mas em direção a uma crescente fluidez. Se tomarmos por oposição as pessoas em fases iniciais de mudança da personalidade, temos pessoas pouco abertas à mudança, rígidas em seu modo de pensar e agir, enquanto as pessoas nas fases mais avançadas são abertas a sua própria experiência conseguindo movimentar-se na vida de acordo com aquilo que está acontecendo no seu presente, tornando-se cada vez mais fluidas.

As pessoas que se encontram no "primeiro estágio" do processo estão distanciadas da sua própria experiência e se encontram num estado de rigidez psicológica. Praticamente não conseguem perceber o movimento espontâneo da própria vida e por isso guiam-se de acordo com as situações que ocorreram em seu passado. Quando diante de uma situação nova, é como se elas olhassem para seu passado para ver como reagiram, é com base nesta experiência do passado que reagirão novamente. Um investidor nesta fase diria: "investir na Vale sempre deu certo e por isso vou continuar comprando, não importa o quanto ela caia". Ele não olhará para as novas informações da empresa como fatos que mudarão o futuro, mas as interpretará de acordo com sua forma rígida de pensar. Este será, muito provavelmente, um investidor conservador com poucas empresas em sua carteira e que comete os mesmos erros. Como não consegue perceber o que se passa na sua experiência imediata, também não percebe estes sentimentos e nem as situações presentes com suas peculiaridades, neste sentido seu jeito de ser não se atualiza, é sempre muito parecido. Naturalmente as pessoas com este perfil são completamente avessas às mudanças, irão reclamar do presente sempre achando que o passado era melhor, o que não é nenhuma surpresa, visto que o passado é seu ponto de referência. Falando de psicoterapia estas pessoas não pedem ajuda por conta própria, uma vez que, pela falta de reconhecimento dos seus sentimentos, acham que estão sempre bem. No entanto, este estar bem não é um sentir-se bem, seria mais correto dizer que é uma incapacidade de sentir qualquer coisa. Estar bem ou não é igual.

Se esta pessoa tiver a possibilidade de se sentir aceita incondicionalmente seguirá para o "segundo estágio". Nesta fase, a experiência da pessoa ainda está determinada pelo seu passado, mas há um leve reconhecimento dos sentimentos, não como algo seu, mas fora, e num momento distante. Cavalcante Junior (2008) explica que a pessoa não reconhece a responsabilidade sobre seus conflitos e refere-se a seus problemas na terceira pessoa. O investidor, que não consegue vender sua posição no começo da queda, colocará a culpa no mercado (ou atribui a falhas técnicas do sistema), dizendo que venderia se o mercado não tivesse andado tão rápido, no seu corretor que demorou na ligação, ou ainda em alguém que tivesse dito alguma coisa sobre não vender, sem olhar para si mesmo como ponto de referência da sua tomada de decisão.

Quando o início deste fluxo não é bloqueado, e a pessoa consegue se sentir aceita, segue para o terceiro estágio. A pessoa começa a expressar a existência do eu, ainda como se fosse um objeto externo, fora dela. Ela consegue refletir sobre o eu na relação com os outros, mas não consigo mesma. Dirá por exemplo: "quando faço isto pareço com a minha mãe", o que mostra o início do reconhecimento do 
próprio eu, mesmo que na comparação com algo externo. Começa a conseguir expressar sua experiência, porém ainda como algo do passado. Da mesma forma, os sentimentos também começam a ser expressos como se estivessem presentes em algum momento do passado, apesar de serem compreendidos na sua maioria como algo ruim, até vergonhoso e anormal, que deve ser evitado. Outra característica deste estágio, relevante para nosso trabalho, é que a pessoa percebe suas escolhas como se fossem ineficazes. Ela quer fazer alguma coisa, e decide fazer, entretanto percebe que não se comporta de forma coerente para realizar tal objetivo. "Eu tinha planejado tudo, iria realizar a venda assim que chegasse a R\$ 22,00, mas na hora não deu". Seria uma fala típica do investidor neste estágio. É como se o objetivo e o seu comportamento não combinassem. Rogers (2001b) explica que a maioria das pessoas que procura ajuda está nesta fase e fica nela por bastante tempo, falando de experiências passadas, descrevendo sentimentos não presentes no momento imediato e falando do seu eu como um objeto. No entanto, depois de preparadas seguem para a próxima fase.

O quarto estágio caracteriza-se por uma maior fluidez de expressão dos sentimentos. Algumas vezes a expressão ocorre no presente, mas na maioria delas ainda são expressos como presentes no passado, apesar de que neste momento de forma mais intensa. A pessoa consegue perceber melhor os seus sentimentos e passa a diferenciá-los de outras reações. Este investidor comentaria que sentiu muita raiva por, outra vez, não ter realizado a posição no valor que tinha se proposto. Ainda há pouca aceitação destes sentimentos, embora às vezes ela já aconteça sem a consciência desta ação. A experiência, a partir deste estágio, é menos determinada pelo passado, ele é mais recente ou quase imediato. Em resumo, a pessoa começa a se perceber melhor. Começa a interessar-se pela sua experiência mais recente e busca compreender melhor o que se passa com ela, tentando encontrar a simbolização exata para as situações que vivem. Digamos que um trader neste estágio, ao observar o mercado mudando de direção no final da tarde, teria a sensação de que seu organismo está dizendo para comprar. Mesmo se já tivesse perdido dinheiro numa compra efetuada diante de uma mudança parecida no mercado, ele poderia perceber a diferença entre os dois momentos, apesar de que no momento imediato talvez ainda não conseguisse comprar. Logo em seguida, como num ato reflexivo sobre a situação, perceberia com clareza os sinais que seu organismo (compreendido aqui no sentido rogeriano, ou seja, que engloba tanto os aspectos psíquicos como os biológicos do ser humano) estava lhe enviando sobre a situação e que antes era apenas uma sensação difusa. É como se ele dissesse: “agora está tão claro!" Esta coloca - se como uma preparação para entrar na fase seguinte, quando os sentimentos passam a ocorrer no presente. Isto não aconteceria com um trader numa fase anterior, pois o fato de ter perdido dinheiro num momento parecido faria com que ele interpretasse tal situação com base naquela, e o medo de perder novamente ficaria mais presente do que a sensação atual.

Conforme avança do quarto para o "quinto estágio", passa a gozar de uma maior liberdade tanto na expressão dos seus sentimentos como na sua aceitação. Os sentimentos ainda se referem ao passado, agora próximo, mas são relatados 
com se estivessem no presente. A pessoa passa a experimentar estes sentimentos mais vividamente, apesar de que com receio de vivenciá-los plenamente e de modo imediato. "Eu sabia que deveria ter comprado, na hora tinha alguma coisa que me dizia, meu coração até bateu mais forte, era como se eu estivesse me preparando para apertar o botão compra!" A impressão é a de que estes sentimentos viriam à tona de uma hora para outra, sem que a pessoa percebesse como estariam se formando dentro de sua vivência imediata. Ela sabe que vivenciou alguma coisa e percebe que não consegue expressá-la com clareza, mas começa a notar que a clareza do que se passa com ela depende do contato que tem consigo mesma, aonde poderá verificar exatamente qual o significado das coisas para ela.

\begin{abstract}
Passa a existir uma permissão pessoal para o contato com o momento presente e para a significação de suas vivências, que tem o potencial de, por meio de movimentos auto-reflexivos, trazerem descobertas importantes para a vida do conhecedor de si mesmo (CAVALCANTE JUNIOR, 2008, p. 36).
\end{abstract}

A etapa seguinte é o "sexto estágio". As pessoas que se encontram nesta fase experienciam os sentimentos com toda a sua riqueza de forma imediata, na medida em que surgem na vivência e são aceitos plenamente, fluindo assim para um fim pleno. Os sentimentos que antes eram bloqueados e não surgiam na consciência podem agora também ser vivenciados de forma plena, sem que a pessoa tenha medo deles. Não é necessário dizer que esta pessoa vive sua experiência no presente atualizando seu autoconhecimento nesta mesma experiência, não esquecendo o seu passado, porém não precisa mais dele como um quadro de referência esta função agora passa a ser exercida pela própria vivência. Este investidor consegue identificar com facilidade que um investimento que deu certo no passado pode não ocorrer novamente, e estará aberto a agir de acordo com o conhecimento que vai se atualizando no presente. Junto com estas características psicológicas ocorre também uma maleabilidade fisiológica: são frequentes os olhos úmidos, as lágrimas, os suspiros e um relaxamento muscular. Rogers (2001b) também acredita que há uma melhora da circulação e da condutividade dos impulsos nervosos.

No "sétimo estágio", os sentimentos tanto negativos como positivos são experimentados com toda a sua riqueza de detalhes no presente imediato e são utilizados como um ponto de referência claro para o autoconhecimento, os desejos e as atitudes. A pessoa consegue confiar nesses sentimentos de forma cada vez maior, percebendo e aceitando também suas mudanças. Nesta fase, o investidor será muito mais confiante na sua intuição, não compreendida aqui como algo místico, mas sim no sentido dado por Espinosa, como uma forma de chegar ao conhecimento mais sofisticado, depois que acumulamos informações suficientes para isto e refletirmos sobre, por meio da razão (DAMÁSIO, 2004). A intuição surge de maneira não reflexiva, muito rápida diante de uma situação, pois é justamente o conhecimento resultante da experiência que engloba as informações adquiridas ao longo da vida, bem como as reflexões da pessoa sobre ela. Este investidor é capaz de confiar na sua intuição, pois sabe que a decisão mais acer- 
tada dependerá somente dele. Além disso, sabe que esta decisão poderá ser modificada quando necessário, sem medo ou remorsos por pequenos prejuízos que fazem parte do caminho. A vivência torna-se cada vez mais fluida e, como cita Cavalcante Junior (2008), a pessoa passa a viver uma vida plena, num processo de mudança contínua sem medos ou defesas, aceitando-se integralmente.

O processo de decisão destas pessoas nas fases finais será baseado na sua estrutura interna de preferências, na qual consegue confiar plenamente. Isto não significa que as escolhas são sempre fáceis de serem feitas e que sempre produzirão o resultado esperado pela pessoa. No entanto, a pessoa que Rogers (2001b, 2005) chama de psicologicamente madura estará aberta à experiência imediata e por isso também é capaz de mudar de direção mais rápida e tomar outras decisões de acordo com as circunstâncias, de forma a modificá-las quando isto for possível e necessário sem ficar presa em decisões passadas. Existe um equilíbrio entre o sistema emocional e o racional que só acontece quando a maturidade psicológica é alcançada (ROGERS; KINGET, 1977). A pessoa age no fluxo da experiência vivida, o que lhe confere mais agilidade, tanto nas decisões como nas ações necessárias para se adaptar a qualquer situação que se faça presente (ROGERS; STEVENS, 1991; ROGERS; KINGET, 1977; ROGERS, 2005). Ela "passa de desconfiança nos aspectos espontâneos e inconscientes de si mesmo para uma confiança básica no que sente, e em seu organismo, como um instrumento seguro para enfrentar a vida" (ROGERS; STEVENS, 1991, p. 55). Esta pessoa aceita seus sentimentos com facilidade e confia na sua natureza íntima como uma força resultante da sua singularidade para saber qual é a melhor forma de agir.

Todas estas etapas fazem parte de um contínuo de mudanças que ocorrerão quando uma pessoa sente-se plenamente aceita em seus sentimentos. A aceitação incondicional pelo outro leva à aceitação dos próprios sentimentos, que poderão então servir de guia para a experiência. Como um resumo do que acontece em termos de sentimentos, Rogers (2001b, p. 179) explica que:

[...] no extremo inferior do contínuo eles são descritos com longínquos, impessoais e não-presentes. Posteriormente são descritos como objetos presentes e em certa medida reivindicados pelo indivíduo. A seguir são expressos como sentimentos pessoais em termos mais próximos da sua experiência imediata. Num grau ainda mais elevado da escala são experimentados e expressos como imediatamente presentes, com um receio decrescente deste processo. Nesse ponto, mesmo os sentimentos que foram anteriormente rejeitados da consciência começam a surgir, são experimentados e cada vez mais reconhecidos pelo indivíduo como seus. No ponto superior do contínuo, no interior do processo da experiência, um incessante fluxo de sentimentos caracteriza daí em diante o indivíduo. 


\section{EMOÇõeS E TOMADA DE DECISÃo}

Como vimos, as emoções e sentimentos humanos são um ponto fundamental na teoria de Rogers, apesar de o autor não ter escrito um livro exclusivamente sobre o assunto. Tambara e Freire (2007, p. 35) mostram que para Rogers uma característica desta terapia é a "maior ênfase aos sentimentos do que a compreensão intelectual". A proeminência do emocional está presente tanto quando Rogers descreve as fases da personalidade em mudança, como nas atitudes terapêuticas que permitem o desabrochar da personalidade madura: a empatia, a congruência e a aceitação incondicional.

A empatia é o que nos permite compreender o outro, não apenas em suas palavras e atitudes, mas na profundidade do seu ser emocional (ROGERS; KINGET, 1977; ROGERS, 1997, 2001a, 2001b, 2005; SANTOS; ROGERS; BOWEN, 2004; ROGERS; ROSENBERG, 2002; CAVALCANTE JUNIOR, 2008). Empatia significa entender o outro do ponto de vista deste outro, e não do seu próprio. É olhar a partir do quadro de referência interna dele, ou dela, para entender o mundo com suas emoções e seus significados (ROGERS; ROSENBERG, 2002). Ser empático significa captar os significados que são próprios da outra pessoa, para compreender o que se passa no seu íntimo, e poder comunicar para ele ou ela um pouco desta compreensão que se tem do seu mundo (ROGERS; KINGET, 1977; ROGERS 1997, 2001a, 2001b, 2005; SANTOS; ROGERS; BOWEN, 2004; ROGERS; ROSENBERG, 2002; ANDRADE; CAVALCANTE JUNIOR, 2008). Para isso é preciso viver sua vida por uns breves instantes, a fim de perceber, sem colocar nossos próprios significados, preconceitos e valores, mas somente os da pessoa em questão, para entender o que ela ainda não percebe com muita clareza, revelando esta percepção. No entanto, isto deve ser feito com muito cuidado para não dar um passo a frente daquilo que está sendo mostrado (ROGERS: ROSENBERG, 2002).

Com o termo congruência, Rogers queria dizer ser o que se é de fato. Estar congruente é agir de acordo com os próprios sentimentos, aceitando-os e compreendendo-os como guia interno para nossas escolhas (ROGERS; KINGET, 1977; ROGERS, 1997, 2001a, 2001b, 2005; SANTOS; ROGERS; BOWEN, 2004; ROGERS; ROSENBERG, 2002; ANDRADE; CAVALCANTE JUNIOR, 2008). Em outras palavras, significa poder reconhecer o que se passa no nosso íntimo, para poder exprimir sentimentos e atitudes conforme surgem, dentro do fluxo contínuo da experiência, sem ficar repetindo os padrões de experiências passadas, ou analisando as coisas de maneira consciente. Ser congruente é reagir de acordo com a percepção interna do organismo, confiando nele como um guia eficaz para o comportamento. Em uma só palavra, pressupõe ser autêntico (EVANS; ROGERS, 1979; ROGERS, 2005).

A aceitação incondicional nada mais é do que a aceitação dos sentimentos do semelhante. Aceitar o outro incondicionalmente é aceitá-lo como ele é. É não fazer julgamentos, não exprimir juízos de valor. Quem é capaz de tal atitude aceitará o outro, não importa qual for o sentimento: medo, angústia, tristeza, raiva, orgulho, inveja, alegria. (ROGERS, 2001a, 2001b, 2005). Aceitar o outro, desta forma, per- 
mite que ele recupere a auto - estima ou amor próprio perdido pelas experiências de amor condicional espalhada ao longo de sua vivência. A auto - estima fica comprometida pela impossibilidade de satisfação da necessidade de ser aceita como um indivíduo de valor quando criança, o que leva a perda da confiança em si e impede o desenvolvimento de uma personalidade integral (AXLINE, 1980).

Na última década, as emoções vêm ganhando destaque dentro da psicologia científica e da neurociência. Em 1994, Damásio publicou a primeira versão, em inglês, do seu importante livro - O Erro de Descartes - onde relata suas pesquisas com pessoas que tiveram lesões cerebrais em áreas relacionadas com a emoção e mostra como elas ficaram impossibilitadas de tomar decisões. Estas pessoas ficavam perdidas pesando todas as consequências possíveis para cada escolha relacionada com a decisão que precisavam tomar e jamais chegavam a uma solução. Damásio (2007) propõe então a hipótese do marcador somático, mostrando que as emoções têm um peso nas decisões humanas, pois marcam visceralmente as respostas com maior probabilidade de gerar consequências negativas com base na história de vida da pessoa.

As emoções recebem com isto o status científico de importância vital na nossa motivação para agir. Martins (2004) afirma que emoções são como forças críticas na construção do mundo contemporâneo, sendo o seu conhecimento necessário para a compreensão da vida em sociedade. As emoções são compreendidas como "a primeira reação global do organismo, a primeira forma de interação e de sincronização do organismo inteiro com a realidade" (MARTINS, 2004, p. 29). Elas são de importância vital para nós: ao mesmo tempo em que nos despertam a atenção para uma situação importante em que uma reação rápida é necessária, preparam nosso corpo para tal ação. Assim, a tristeza nos ajuda a deixar ir o que já acabou, abrindo espaço para o novo; o medo nos prepara para fugir ou lutar; o nojo faz com que evitemos algo que poderia ser nocivo para nossa saúde (MARTINS, 2004).

A palavra emoção deriva do latim e-movere, que significa mover a partir de dentro. São as emoções que nos movem (MARTINS, 2004) e fornecem as bases rumo as nossas realizações de longo prazo (LEDOUX, 2001). Damásio (2007) relata casos de escolhas de vidas catastróficos que levam ao fracasso na vida afetiva e financeira de pacientes sem capacidade de sentir emoções.

Entretanto, no mundo das finanças, as emoções ainda são compreendidas como o oposto da razão. Um exemplo disso pode ser verificado no livro de Debastiani (2007), dedicado aos investidores. Debastiani (2007, p. 165) explica que "É preciso manter a cabeça fria quando incorremos em perdas, não deixando que os sentimentos contaminem nossa lógica de trabalho e nossa disciplina no mercado". Martins (2004) considera que a distinção entre razão e emoção ocorreu com algumas correntes predominantes da psicologia por muito tempo e tem relação com as correntes filosóficas que enfatizam a importância do controle emocional para a vida em sociedade, as quais influenciaram a psicologia enquanto ciência embrionária. Atualmente já se sabe que as emoções têm uma 
função adaptativa útil ao organismo, chamando nossa atenção para uma situação importante que está sendo vivenciada. Elas influenciam diretamente nossa percepção da realidade (MARTINS, 2004).

Contudo, se a neurociência descobriu, recentemente, a relação das emoções e da razão, não seria justo deixar de dizer que algumas linhas da psicologia já lhe conferiam importância crucial, não só na decisão, mas na vida humana como um todo, como é o caso da psicologia fenomenológica. Sartre, em 1939, publica o Esboço para uma teoria das emoções, em que aponta para a impossibilidade de conhecer as emoções humanas sem olhar para o significado que elas possuem para aquele que as está sentindo. A compreensão deve ser buscada, não em leis e estruturas gerais, mais sim "nos processos da própria emoção" (SARTRE, 2006[1939], p. 19).

As emoções, como concordam Damásio (2004, 2007) e Rogers (1997, 2005), servem como um guia efetivo para o comportamento humano. Entretanto, há uma diferença entre estes dois autores que é preciso apontar: para Damásio (2004, 2007), a tomada de decisão fica impossibilitada pela ausência de emoções, enquanto que para Rogers $(1997,2005)$, quando elas são distorcidas pelo processo de vida da pessoa levam a interpretações incorretas da realidade e conseqüentemente a decisões erradas (ROGERS, 1997, 2005; MARTINS, 2004). Para este autor, a pessoa com sentimentos autênticos (não distorcidos) consegue compreender o que ocorre no seu íntimo e é capaz de confiar nisto, o que tem como reflexo um comportamento adequado à situação (ROGERS, 1997, 2005). Rogers e Stevens (1991, p. 27) explicam que

O Adulto psicologicamente maduro acredita na sabedoria de seu organismo e é capaz de utilizá-la [...] Compreende que é possível confiar totalmente em si mesmo, que suas intuições e sentimentos podem ser mais razoáveis que sua mente, que como uma pessoa completa pode ser mais sensível e correta do que apenas com os seus pensamentos.

As emoções autênticas possuem um objetivo específico no sentido da nossa sobrevivência ou da sobrevivência da espécie, seja concreta ou simbólica. Mas isto só ocorre com as pessoas que se encontram nas fases mais avançadas do processo de mudança da personalidade. Nas fases anteriores, as emoções estão distorcidas e levarão a formas distorcidas de perceber a realidade. Somente as emoções autênticas são úteis em direção ao processo de crescimento do organismo, são confiáveis e servem de guias eficazes para o comportamento. Emoções distorcidas não cumprem mais este objetivo, perderam esta função específica por sofrerem interrupção durante algum tempo, no processo de educação. Martins (2004) inclui nesta categoria também as emoções instrumentais, padrões emocionais que as pessoas aprendem a utilizar para obter um resultado específico, que também não cumprem a função original. 


\section{A DiSTORÇÃo das EMOÇões e SUAS CONSEQUÊnCIAS NA TOMADA DE DECISÃo}

A diferença entre emoções distorcidas e autênticas há muito já foi relatada por Rogers, sendo um dos pilares de sustentação de sua teoria. Esta pessoa que não consegue agir de forma congruente não consegue confiar na sua experiência imediata para decidir qual o caminho a seguir. Ela está tão acostumada a fazer o que os outros the dizem ou seguir aquilo que aprendeu a fazer no decorrer de sua vida que é assim que vai continuar agindo. Ao invés de avaliar uma situação presente da forma como ela está acontecendo, agora, na sua experiência, ela irá avaliá-la de acordo com a experiência passada (ROGERS, 2001b; ROGERS; KINGET, 1977).

Vamos tomar um exemplo para facilitar a compreensão. Digamos que uma criança estava almoçando com seu pai quando um alimento novo lhe foi apresentado. Seu pai disse que não gostava de tal alimento e que ela não deveria experimentar porque era muito ruim. A criança, já achando que a aparência de tal alimento não lhe agradava, não experimentou e aprendeu que aquilo era ruim. A partir daí nunca mais experimenta tal alimento, pois toda vez que entra em contato com ele avalia que não gosta devido à experiência do passado. Desta forma, nunca poderá descobrir o gosto que tem e nem mesmo como seu sabor se modifica quando adicionado a outros alimentos, dando origem a uma receita culinária diversa.

Agora vamos tentar mostrar outro exemplo na área dos investimentos. Supúnhamos que, depois de uma longa e detalhada análise do mercado, está mesma pessoa, agora já adulta, tenha comprado algumas ações da Petrobrás. Passando-se alguns dias da compra, a primeira no mercado de ações da sua história, as ações sofrem uma grande queda. O investidor resolve que é melhor vendê-las, porque precisa do dinheiro para alguma outra coisa. Daí por diante, este investidor resolve que não comprará mais ações da Petrobrás, pois não é possível ganhar dinheiro com esta empresa. Na minha experiência enquanto professora, tive vários alunos que depois de perderem dinheiro com alguma ação, afirmaram não conseguir nem mais olhar para tal empresa. O mesmo pode acontecer no sentido inverso. Digamos que o investidor tivesse comprado ações da Vale e ganhasse dinheiro com elas. Depois de algum tempo as ações vem a cair, mas ele não vende, pois aprendeu que ações da Vale só dão lucro, e mesmo que venham a cair abaixo do preço que pagou poderá não conseguir se desfazer delas.

Esta falta de confiança não ocorre de um momento para o outro, e nem basta uma única situação, como foi colocado acima, a título de exemplo. Um investidor que age assim, desconfiando daquilo que sente no seu íntimo, já age desta forma na sua vida, porque suas decisões de investimentos serão apenas um reflexo de como toma outras decisões na sua vida cotidiana. Examinemos agora como ocorre o processo de distorção de emoções nas nossas vidas.

\section{O PROCESSO DE DISTORÇÃO EMOCIONAL E SUAS CONSEQUÊNCIAS}

Este processo geralmente começa quando a criança ainda é muito pequena. De acordo com a teoria da personalidade de Rogers, a criança pequena percebe a realidade a partir da forma como a experiencia, e age de acordo com ela, experi- 
mentando as coisas que a rodeiam, por exemplo, comendo o que acha gostoso, jogando fora o que acha ruim. Aproxima-se do que a atrai e se afasta do que a repele de maneira natural com base nos seus valores internos. Este processo chama-se valoração organísmica. Quando vai crescendo, começa a tomar consciência de que existe como um indivíduo diferenciado e passa também a sentir como uma necessidade básica ser aceita pelos seus semelhantes. Quando esta necessidade é ameaçada, devido à reprovação de seus sentimentos, ela pode deixar de fazer aquilo que sua experiência pede, para fazer aquilo que o outro gostaria que fizesse. Depois de passar várias vezes por esta experiência, deixa de perceber a realidade a partir do significado da sua experiência e passa a representá-la como é para o outro. Neste momento a personalidade se torna dividida entre o self e a experiência real, o que causa também um conflito no comportamento (ROGERS; KINGET 1977).

Quando esta dissociação ocorre, devido ao processo de educação, o nosso sistema emocional, que nos possibilitaria lutar contra todas as limitações que o mundo nos impõe e superar os obstáculos que se façam presentes, além de suportar as frustrações e a dor, ficam danificados e não cumpre mais seu objetivo. Infelizmente na nossa cultura, a educação da criança, que exige o controle de certos comportamentos, abrange também o controle das emoções, o que não é só desnecessário, mas também prejudicial, levando ao quadro descrito acima. Neste processo de educação, ensina-se à criança que certas coisas não são certas de serem sentidas, que não se pode demonstrar emoções em qualquer situação, que existe a emoção certa para o lugar ou situação certa. Tirar da criança a possibilidade de expressar suas emoções, como chorar quando está triste, por exemplo, é tirar dela as condições que a natureza lhe forneceu para lidar com situações difíceis, restaurando as condições para voltar à ação, pois é frustrada também a capacidade de equilíbrio que o processo emocional favorece. Quando as emoções não encontram vias de expressão podem tornar-se "acumuladas" e aí sim levar a comportamentos impulsivos que não parecem adaptados à situação atual (MARTINS, 2004).

Este processo de dissociação da personalidade e seus consequentes danos para o sistema emocional humano estão também relacionados. Como tentamos mostrar neste artigo, há investimentos e trades fracassados decorrentes de percepções rígidas e seus comportamentos inadequados, levando a prejuízos frequentes no mundo dos investimentos. Como exemplo, para finalizar, podemos citar alunos investidores ou traders impulsivos, que apesar de perceberem que não é a hora certa de comprar ou vender, não têm paciência o suficiente para esperar o momento que consideram certo. Um aluno, em uma aula de simulação, depois de efetuar uma compra ficou com suas mãos trêmulas e mantinha-se totalmente agitado, acalmando-se somente depois que liquidou seu negócio. Muitos, dependendo do estágio de desenvolvimento da personalidade em que se encontram, até percebem que são impacientes demais, porém mesmo assim não conseguem modificar seu comportamento. Isto não ocorre com aqueles que estão nas fases finais, cuja maturação psicológica se aproxima da ótima. 


\section{Considerações Finais}

A tomada de decisão vem sendo estudada pela economia para mostrar como se formam os preços nos mercados. Pesquisas realizadas pelas finanças comportamentais, uma área dentro da psicologia econômica, mostram que esta teoria apresenta falhas quando os investidores são colocados em situações práticas, ou seja, não agem como a teoria pressupõe. Neste sentido, é enumerada uma série de erros que ocorrem em relação à vida prática e à teoria econômica, que são chamados de anomalias.

As pesquisas das finanças comportamentais, utilizando-se do referencial teórico da psicologia cognitiva, têm conseguido um grande avanço para a compreensão dos aspectos cognitivos do processo decisório. Nosso estudo apresentou uma proposta de compreensão dos aspectos emocionais envolvidos neste processo, utilizando-se da Abordagem Centrada na Pessoa como referencial teórico. Por este enfoque, nossas decisões podem ser mais assertivas e flexíveis, quando o processo emocional não sofreu distorções durante nosso desenvolvimento. Quando o processo é distorcido, as decisões permanecem rígidas, pois são tomadas com base nas nossas experiências passadas sem espaço para atualização na experiência única do presente. Para mudar esta situação é necessário que haja uma atualização da personalidade num ambiente de congruência, empatia e aceitação incondicional, onde a personalidade possa desenvolver-se integralmente.

Deste modo, acreditamos que quando um investidor consegue olhar para si, de modo a entender e a aceitar suas emoções autênticas, seu processo de tomada de decisão ocorrerá com mais facilidade e assertividade. Isto não significa que sempre irá acertar o sentido do mercado, mas que estará apto para tomar medidas adaptativas, como mudar de posição, ajustar um stop, ou mesmo sair da posição (seja com lucro ou prejuízo) para observar "de fora", com clareza, uma vez que perceberá, com mais discernimento e rapidez, a fluidez do mercado.

Este trabalho foi um estudo bibliográfico e exploratório sobre o tema e seria importante a realização de futuras pesquisas, como, por exemplo, estudos de casos e pesquisas documentais com base nos fóruns de investidores, ou questionários enviados a corretoras, para uma maior compreensão da tomada de decisão dentro deste enfoque. Trabalhos posteriores poderão tornar-se úteis tanto para a área de finanças como para a psicologia. Para a primeira, ampliar os já reconhecidos conhecimentos das finanças comportamentais a fim de dar conta também dos fatores emocionais; para a segunda, proporcionar novos campos de pesquisa e formas de atuação para psicólogos. Para finalizar, esperamos que este trabalho pudesse despertar nos psicólogos algum interesse pela área de investimentos da mesma forma como a psicologia vem despertando nos economistas. 


\section{GlossáRIO}

Ações - Representam a menor parcela do capital social da empresa, o acionista torna-se proprietário da empresa na quantidade correspondente de ações que possui, tendo entre seus direitos, a participação nos resultados da empresa, caso houver (PINHEIRO, 2002).

Acionista - Qualquer pessoa que possua ações da empresa.

Análise de investimentos - Teorias que auxiliam o investidor a encontrar as melhores ações, aceitas academicamente ou pelo senso comum.

Bolsa de Valores - "As bolsas de valores são instituições civis, sem fins lucrativos, constituídas pelas corretoras de valores para fornecer a infra-estrutura do mercado de ações" (FORTUNA, 2005).

Carteira- Conjunto de ações.

Corretora- Faz a intermediação entre os compradores e os vendedores. É necessário que cada investidor tenha uma conta em alguma corretora.

Dividendos - Lucros distribuídos aos acionistas.

Stop - Termo utilizado para designar um limite de perdas estipulado pelo investidor.

Pregão - "É o recinto onde ocorrem as negociações entre representantes das sociedades corretoras de títulos e valores mobiliários" (PINHEIRO, 2002).

Trader - Investidor de curto prazo que procura ganhar com as oscilações diárias do mercado.

\section{REFERÊNCIAS}

ANDRADE, A. B. ; CAVALCANTE JUNIOR, F. S. A Expressão da Tendência Formativa em Ludoterapia Centrada na Criança. In: Francisco Silva Cavalcante Junior; André Feitosa de Sousa (Org.). Humanismo de Funcionamento Pleno: Tendência Formativa na Abordagem Centrada na Pessoa - ACP. Campinas: Alínea, 2008. p. 157-189.

AXLINE, V. M. Ludoterapia. 2. ed. Tradução de Carl R. Rogers. Belo Horizonte: Interlivros, 1980.

BELLO, A. A. Introdução à Fenomenologia. Tradução de Jacinta Turoldo Garcia e Miguel Mahfoud. Bauru: EDUSC, 2006.

CASTRO JUNIOR, F. H. F.; FAMÁ, R.As novas finanças e a teoria comportamental no contexto da tomada de decisão sobre investimentos. Caderno de Pesquisa em Administração, São Paulo, v. 09, n. 2, p. 25-35, abr./jul. 2002. 
CAVALCANTE JUNIOR, F. S. Psicologia Humanista Experiencial. In: CAVALCANTE JUNIOR, F. S.; SOUSA, A. F. de; FEITOSA, A. (Org.). Humanismo de Funcionamento Pleno: Tendência Formativa na Abordagem Centrada na Pessoa - ACP. Campinas: Alínea, 2008. p. 21-43.

CAVALCANTE FILHO, F. S.; MISUMI, J. Y. Mercado de capitais. 4. ed. Rio de Janeiro: Campus, 2001.

DAMASIO, A. R. O mistério da Consciência . Tradução de Laura Teixeira Motta. São Paulo: Companhia das Letras, 2000.

DAMASIO, A. R. Em busca de Espinosa: prazer e dor na ciência dos sentimentos. 2. ed. São Paulo: Companhia das Letras, 2004.

DAMASIO, A. R. O erro de Descartes. 2. ed. Tradução de Dora Vicente e Georgina Segurado. São Paulo: Companhia das Letras, 2007.

DAMODARAN, A. Filosofias de investimento: estratégias bem-sucedidas e os investidores que as fizeram funcionar. Tradução de Carlos Henrique Trieschmann. Rio de Janeiro: Qualitymark, 2006.

DAMODARAN, A. Avaliação de Empresas. 2. ed. Tradução de Marcelo Arantes Alvin e Sonia Midori Yamamoto. São Paulo: Pearson, 2007.

DEBASTIANI, C. A. Candlestick: um método para ampliar lucros na Bolsa de Valores. São Paulo: Novatec, 2007.

EVANS, R.; ROGERS, C. R. O homem e as suas idéias. São Paulo: Martins Fontes, 1979.

FERREIRA, V. R. M. Psicologia Econômica: estudo do comportamento econômico e da tomada de decisão. São Paulo: Elsevier, 2008.

FLEURIET, M. A arte e a ciência das finanças: uma introdução ao mercado financeiro. Tradução de Maria José Cyhlar Monteiro. Rio de Janeiro: Campus, 2004.

FORGHIERI, Y. C. Psicologia fenomenológica. Perdizes: Pioneira, 1993.

FORTUNA, E. Mercado Financeiro: produtos e serviços. 16. ed. Rio de Janeiro: Qualitymark, 2005.

JOURNAL OF ECONOMIC PSYCHOLOGY. [S.1.]: Elsevier, 1981- . 
KAHNEMAN, D. Maps of Bounded Rationality: a perspective on intuitive judgment and choice. The Nobel Foundation, p. 449-489, Dec. 2002. Disponível em: <http://nobelprize.org/nobel_prizes/economics/laureates/2002/kahnemannlecture.pdf $>$. Acesso em: 12 jun. 2004.

KAHNEMAN, D. Maps of Bounded Rationality Psychology for Behavioral Economics. The American Economic Review, [S.1.], v. 90, n. 5, p. 1449-1475, Dec. 2003.

LEDOUX, J. O Cérebro Emocional: os misteriosos alicerces da vida emocional. Tradução de Terezinha Batista dos Santos. Rio de Janeiro: Objetiva, 2001.

MARTINS, J. M. A lógica das emoções na ciência e na vida. Petrópolis: Vozes, 2004.

MILANEZ, D. Y. Finanças Comportamentais no Brasil. 2003. Dissertação (Mestrado)-Faculdade de Economia, Administração e Contabilidade Universidade de São Paulo, São Paulo, 2003. Disponível em: <http://www.teses. usp.br/teses/disponiveis/12/12140/tde-09022004-130012/>. Acesso em: 20 jun. 2004.

PINHEIRO, J. L. Mercado de capitais: fundamentos e técnicas. 2. ed. São Paulo: Atlas, 2002.

ROGERS, C. R. Psicoterapia e Consulta Psicológica. Tradução de Manuel José do Carmo Ferreira. São Paulo: Martins Fontes, 1997.

ROGERS, C. R. Sobre o poder pessoal. 4. ed. Tradução de Wilma Millan Alves Penteado. São Paulo: Martins Fontes, 2001a.

ROGERS, C. R. Tornar-se pessoa. 5. ed. 3. tir. Tradução de Manuel Jose do Carmo Ferreira e Alvamar Lamparelli. São Paulo: Martins Fontes, 2001b.

ROGERS, C. R. Um jeito de Ser. 6. reimp. Tradução de Maria Cristina Machado Kupfer, Heloísa Lebrão e Yone Souza Patto. São Paulo: E.P.U., 2005.

ROGERS, C. R.; KINGET, G. M. Psicoterapia e Relações Humanas. 2. ed. Tradução de Maria Luiza Bizzotto. Belo Horizonte: Interlivros, 1977. v. 1.

ROGERS, C. R.; ROSENBERG, R. A Pessoa como centro. 10. reimp. São Paulo: EPU, 2002.

ROGERS, C. R; STEVENS, B. De pessoa para pessoa. 4. ed. Tradução de Mirian L. Moreira Leite e Dante Moreira Leite. São Paulo: Pioneira, 1991. 
SANTOS, A. M.; ROGERS, C. R.; BOWEN, M. C. V. B. Quando Fala o Coração: a essência da Psicoterapia Centrada na Pessoa. São Paulo: Vetor, 2004.

SARTRE, J. P. Esboço para uma teoria das emoções (1939). Tradução de Paulo Neves. Porto Alegre: L\&PM, 2006.

SternberG, R. J. Psicologia Cognitiva. Tradução de Maria Regina Borges. Porto Alegre: Artes Médicas Sul, 2000.

TAMBARA, N.; FREIRE, E. Terapia Centrada no Cliente: um caminho sem volta. Porto Alegre: Delphos, 2007.

VALOR ECONÔMICO. São Paulo: Folha de São Paulo / O Globo, 2000- .

Recebido em: junho de 2009

Aceito em: agosto de 2010 